\title{
Full Cementation in Revision Total Knee Arthroplasty Using a Constrained Condylar Knee Prosthesis with an Average 7-Year Follow-up
}

\author{
Ki-Tae Kwon, MD, Kye-Young Han, MD, Woon-Sang Lee, MD, and Do-Hoon Kim, MD \\ Department of Orthopedic Surgery, Kangwon National University School of Medicine, Chuncheon, Korea
}

\begin{abstract}
Purpose: To evaluate clinical and radiological outcome of the full cementation technique in revision total knee arthroplasty (TKA) using a constrained condylar knee (CCK) prosthesis.

Materials and Methods: Between January 2008 and March 2012, 18 cases (16 patients) of fully cemented revision TKA were performed using a CCK prosthesis. Fifteen cases of aseptic loosening (13 patients) and 3 cases of infection were included. There were 2 males and 14 females with a mean age of 76.7 years at the time of surgery, and the average follow-up was 81 months. Clinically, the pain score, function score and Hospital for Special Surgery (HSS) score were evaluated. Radiologically, loosening, radiolucent lines and migration of implant were evaluated.

Results: Preoperatively, the pain score, function score and HSS score were 50.3, 24.4 and 61.8 points, respectively. At the latest follow-up, the scores were improved to $84.8,63.6$ and 85.6 points, respectively $(\mathrm{p}<0.05)$. Loosening or migration of implant was not observed in any cases. Radiolucent lines were observed in 5 cases underneath the tibial component without progression during the follow-up.

Conclusions: The full cementation technique in revision TKA using a CCK showed excellent clinical results. Although radiolucent lines were observed in $27.8 \%$ underneath the tibial component, there was no progression to loosening or instability.
\end{abstract}

Keywords: Knee, Arthroplasty, Revision, Constrained condylar prosthesis, Cementation

\section{Introduction}

The increasing number of total knee arthroplasties (TKAs) has led to a concomitant increase in revision surgeries ${ }^{1-3}$. The restoration of lost bone support and joint stability is the main challenge in revision $\mathrm{TKA}^{4}$. The choice of implant type is based on accurate assessment of ligament quality, bone loss and component fixation; the least degree of constraint necessary is recommended $^{5}$. In the case of revision surgery, the bone stock is often

Received January 9, 2017; Revised (1st) April 28, 2017;

(2nd) May 29, 2017; (3rd) August 2, 2017; Accepted August 28, 2017

Correspondence to: Kye-Young Han, MD

Department of Orthopedic Surgery, Kangwon National University

School of Medicine, 1 Gangwondaehak-gil, Chuncheon 24341, Korea

Tel: +82-33-258-2308, Fax: +82-33-258-9291

E-mail: hkyljh@kangwon.ac.kr

This is an Open Access article distributed under the terms of the Creative Commons Attribution Non-Commercial License (http://creativecommons.org/licenses/by-nc/4.0/) which permits unrestricted non-commercial use, distribution, and reproduction in any medium, provided the original work is properly cited. impaired. Vince and Long ${ }^{6}$ mentioned a press-fit mechanism in the hybrid fixation technique provided no sufficient fixation in cases with impaired bone quality. Recently, well-designed press fit stems have been introduced and shown excellent results ${ }^{7}$; however, still there are some debates on the type of fixation, full cementation or hybrid cementation ${ }^{8}$.

In this study, we analyzed clinical and radiological outcome of fully cemented revision TKA using a constrained condylar knee (CCK) prosthesis.

\section{Materials and Methods}

From January 2008 to March 2012, 18 revision TKAs performed in 16 patients who were available for more than 4-year follow-up were included in this study. This study was approved by the Institutional Review Board of our hospital before commencing the study.

The study population included 14 females (16 knees) and 2 males ( 2 knees). At the time of revision surgery, the median age 
of patients was 76.7 years (range, 51 to 85 years), and the median follow-up period was 81 months (range, 53 to 103 months). The preoperative diagnosis was aseptic loosening in 13 patients (15 knees) and infection in 3 patients ( 3 knees). The median time from the primary knee replacement to revision was 78 months (range, 24 to 156 months). All demographic data are summarized in Table 1.

A medial parapatellar approach was used in all cases. A rectus snip or quadriceps turndown procedure was not required for exposure and removal of implants. All cases were operated with the Legacy constrained condylar prosthesis (Zimmer, Warsaw, IN, USA). Femoral and tibial stems were used in all cases. The canal was 1-2 mm over-reamed for the real stem fixation. The full cementation technique was used for implant fixation. Including the stem tip, the cement was filled into the canal using a finger technique. After insertion and consolidation of the tibial component, femoral component fixation was done with new cement. Three knees with infection were managed by two-stage revision TKA. At first, removal of the infected implant, thorough debridement and irrigation were done. An antibiotic-impregnated mobile cement spacer was used for 8 to 16 weeks till a normal level of C- reactive protein was obtained. After control of infection, antibiotic-mixed (1 g vancomycin/40 g Palacos cement) fully cemented revision TKA was done.

After removal of implants, bony defects were evaluated according to Anderson Orthopedic Research Institute (AORI) classification. On the femoral side, there were 5 cases of $\mathrm{F} 1$ defect and 13 cases of F2 defect. On the tibial side, there were 11 cases of T2 defect and 7 cases of T3 defect. Various femoral and/or tibial augment was used to fill the bone defect. In 7 cases, the medial tibial bone defect was too large to manage with one metal block; therefore, one metal block was initially affixed to the tibial tray using screws, and then more (1-3) metal blocks were attached to the first block with cement (Fig. 1).

For clinical assessment, range of motion (ROM) of the knee joint, Knee Society score (KSS; pain score and function score) $)^{9)}$ and Hospital for Special Surgery (HSS) score were evaluated preoperatively and annually thereafter. For radiological assessment, the alignment of the limb, the position of the components, and the presence and location of all radiolucent lines at the cementbone interface were evaluated ${ }^{9}$. Infection, aseptic loosening and periprosthetic fracture were evaluated as complications.

Table 1. Demographic Data of the Patients

\begin{tabular}{|c|c|c|c|c|c|c|c|}
\hline Case & $\begin{array}{l}\text { Age } \\
(\mathrm{yr})\end{array}$ & Sex & Direction & $\begin{array}{c}\text { Diagnosis } \\
\text { (TKA) }\end{array}$ & $\begin{array}{l}\text { Diagnosis } \\
\text { for TKA }\end{array}$ & $\begin{array}{c}\text { Time from Primary TKA } \\
\text { to revision TKA (mo) }\end{array}$ & $\begin{array}{c}\text { AORI } \\
\text { classification }\end{array}$ \\
\hline 1 & 75 & $\mathrm{~F}$ & $\mathrm{R}$ & Loosening & $\mathrm{OA}$ & 48 & $\mathrm{~F} 1, \mathrm{~T} 2$ \\
\hline 2 & 76 & $\mathrm{~F}$ & $\mathrm{~L}$ & Loosening & OA & 37 & $\mathrm{~F} 2, \mathrm{~T} 2$ \\
\hline 3 & 79 & $\mathrm{~F}$ & $\mathrm{R}$ & Loosening & OA & 36 & $\mathrm{~F} 1, \mathrm{~T} 2$ \\
\hline 4 & 78 & $\mathrm{~F}$ & $\mathrm{~L}$ & Loosening & OA & 43 & $\mathrm{~F} 2, \mathrm{~T} 2$ \\
\hline 5 & 75 & $\mathrm{~F}$ & $\mathrm{~L}$ & Loosening & OA & 48 & $\mathrm{~F} 1, \mathrm{~T} 2$ \\
\hline 6 & 85 & $\mathrm{~F}$ & $\mathrm{R}$ & Loosening & OA & 60 & $\mathrm{~F} 1, \mathrm{~T} 2$ \\
\hline 7 & 82 & $\mathrm{~F}$ & $\mathrm{R}$ & Infected & $\mathrm{OA}$ & 96 & $\mathrm{~F} 2, \mathrm{~T} 3$ \\
\hline 8 & 78 & $\mathrm{~F}$ & $\mathrm{R}$ & Loosening & OA & 61 & $\mathrm{~F} 2, \mathrm{~T} 2$ \\
\hline 9 & 73 & $\mathrm{~F}$ & $\mathrm{~L}$ & Loosening & OA & 52 & $\mathrm{~F} 1, \mathrm{~T} 2$ \\
\hline 10 & 84 & $\mathrm{~F}$ & $\mathrm{R}$ & Loosening & OA & 156 & $\mathrm{~F} 2, \mathrm{~T} 2$ \\
\hline 11 & 75 & $\mathrm{~F}$ & $\mathrm{~L}$ & Loosening & $\mathrm{OA}$ & 84 & $\mathrm{~F} 2, \mathrm{~T} 2$ \\
\hline 12 & 84 & M & $\mathrm{R}$ & Infected & OA & 24 & $\mathrm{~F} 2, \mathrm{~T} 3$ \\
\hline 13 & 51 & M & $\mathrm{R}$ & Infected & OA & 84 & $\mathrm{~F} 2, \mathrm{~T} 3$ \\
\hline 14 & 74 & $\mathrm{~F}$ & $\mathrm{R}$ & Loosening & OA & 108 & $\mathrm{~F} 2, \mathrm{~T} 2$ \\
\hline 15 & 65 & $\mathrm{~F}$ & $\mathrm{R}$ & Loosening & OA & 84 & $\mathrm{~F} 2, \mathrm{~T} 3$ \\
\hline 16 & 85 & $\mathrm{~F}$ & $\mathrm{R}$ & Loosening & OA & 120 & $\mathrm{~F} 2, \mathrm{~T} 3$ \\
\hline 17 & 75 & $\mathrm{~F}$ & $\mathrm{~L}$ & Loosening & $\mathrm{OA}$ & 96 & $\mathrm{~F} 2, \mathrm{~T} 3$ \\
\hline 18 & 73 & $\mathrm{~F}$ & $\mathrm{R}$ & Loosening & OA & 72 & $\mathrm{~F} 2, \mathrm{~T} 3$ \\
\hline Mean & 76.7 & & & & & 72.72 & \\
\hline
\end{tabular}

TKA: total knee arthroplasty, AORI: Anderson Orthopedic Research Institute, R: right, OA: osteoarthritis, F: femoral, T: tibial, L: left. 

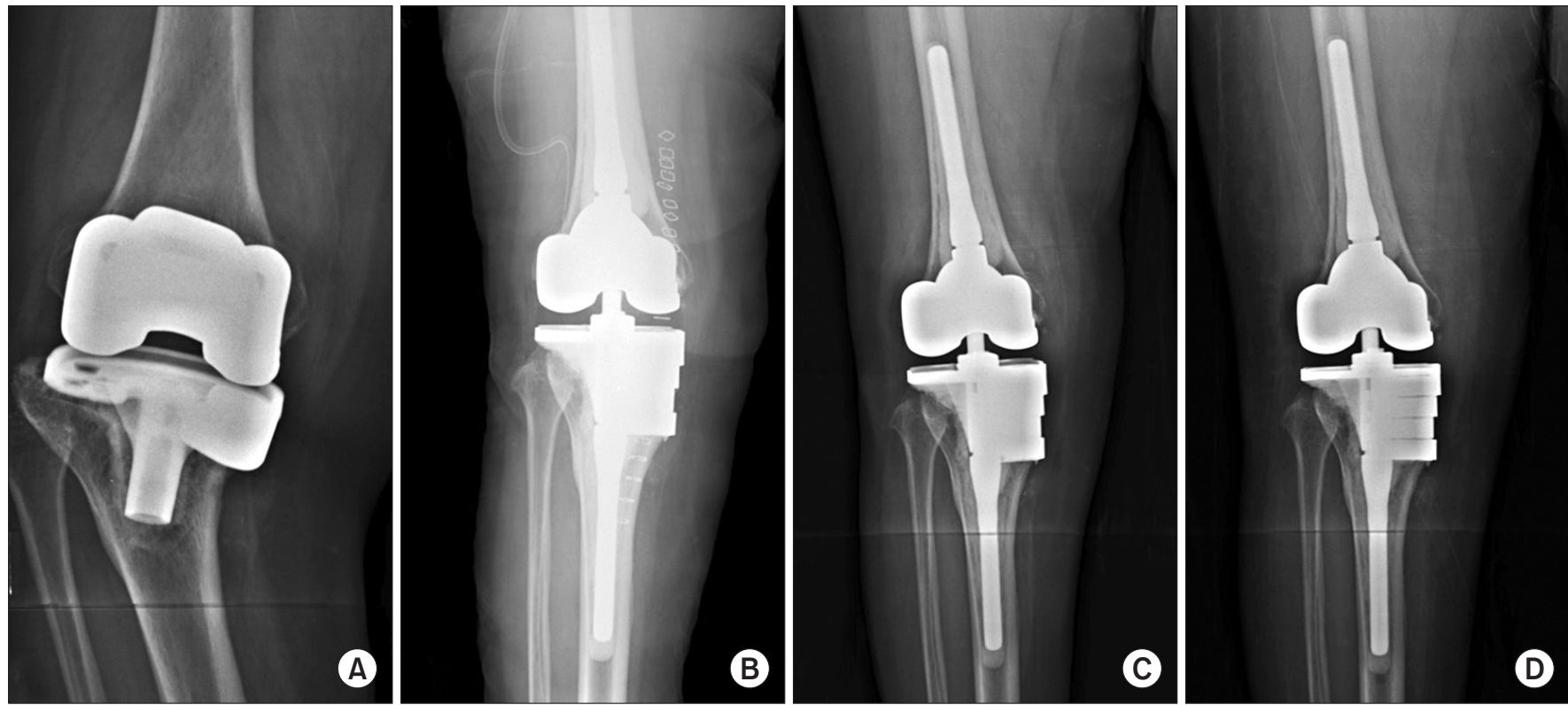

Fig. 1. (A) Preoperative X-ray showing medial collapse and loosening of the tibial component. (B) For reconstruction of the huge bone defect, additional three 10-mm metal augments were used. (C) Postoperative 1-year X-ray showing the well-maintained prosthesis. (D) No radiolucent line or loosening was observed at postoperative 7-year follow-up.

The Mann-Whitney test was used to compare the difference between preoperative values and final follow-up results (ROM of the knee joint, KSS and HSS score). The level of significance was set at $\mathrm{p}<0.05$. Statistical analysis was performed using SPSS ver. 18.0 (SPSS Inc., Chicago, IL, USA).

\section{Results}

The mean KSS pain score was 50.3 points (range, 26 to 75 points) before the operation and 84.8 points (range, 37 to 100 points) at the final follow-up ( $\mathrm{p}=0.000)$. The mean KSS function score improved significantly from 24.4 points (range, 5 to 65 points) to 63.6 points (range, 20 to 100 points) ( $\mathrm{p}=0.000$ ). Also, the HSS score improved from 61.8 points (range, 40 to 75 points) to 85.6 points (range, 48 to 100 points). But, the median ROM was not improved significantly from $110.3^{\circ}$ (range, $70^{\circ}$ to $130^{\circ}$ ) preoperatively to $119.4^{\circ}$ (range, $85^{\circ}$ to $130^{\circ}$ ) at the final followup $(\mathrm{p}=0.171)$. Cases with aseptic loosening and infection showed no significant differences compared to those without in terms of postoperative KSS pain score ( $\mathrm{p}=0.250$ ), KSS function score $(\mathrm{p}=0.654)$, HSS score $(\mathrm{p}=0.250)$ and ROM $(\mathrm{p}=0.426)$.

Preoperative mean knee alignment was varus $5.44^{\circ}$ (range, $21.21^{\circ}$ varus to $16.25^{\circ}$ valgus). The mean knee alignment was valgus $5.29^{\circ}$ (range, $1.11^{\circ}$ varus to $12.21^{\circ}$ valgus) immediately postoperatively and valgus $5.05^{\circ}$ (range, $0.8^{\circ}$ varus to $11.23^{\circ}$ valgus) at the last follow-up. There was no component migration, but radiolucent lines were observed in 5 cases underneath the tibial component. Radiolucent lines were observed at the lateral tibial interface in 2 cases and at both the medial and lateral interfaces in 3 cases (Fig. 2). All radiolucent lines were observed at the cement bone interface. In 3 cases, the radiolucent line width increased during the follow-up, but it did not extend to the stem area and was confined underneath the tibial component. There were no radiolucent lines around the femoral component.

As a complication, infection occurred in one loosening revision case at postoperative five months, so two-stage re-revision TKA was done without recurrence. Aseptic loosening or periprosthetic fracture was not observed during the follow-up period.

\section{Discussion}

To overcome bone loss and ligament damage in revision TKA, a more constrained implant is recommended, and augmentation is commonly used to compensate for bone defects ${ }^{7,10,11}$. Vasso et al. ${ }^{12)}$ recommend the use of a constrained implant according to AORI classification determined based on the state of collateral ligaments and other peripheral stabilizers of the knee and on the severity of bone loss. The CCK system can be used in case of collateral ligament insufficiency and moderate (type 2) bone loss. In our series, the CCK prosthesis was used in all patients even in those with the F1 defect because we had no idea how to use the posterior stabilized insert; however, in T3 defect cases, due to full 

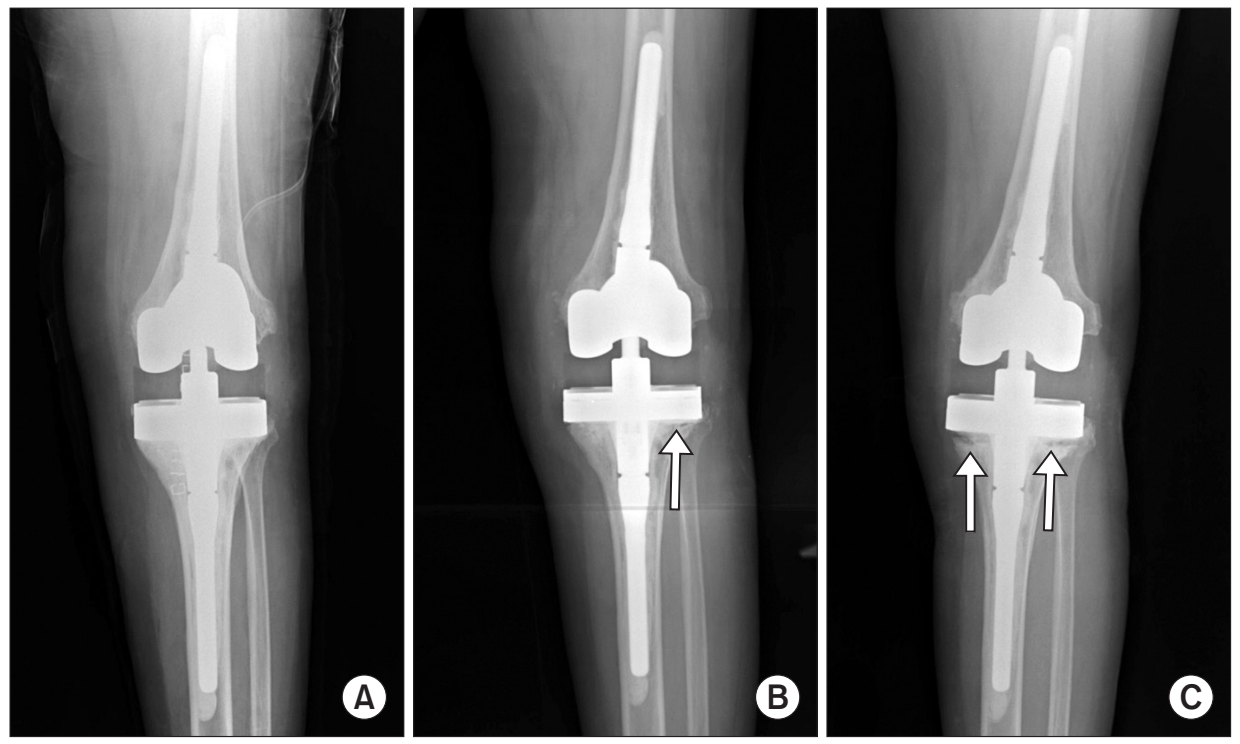

Fig. 2. (A) Immediate postoperative X-ray. (B) A radiolucent line (white arrow) was observed underneath the lateral tibial component at 1-year follow-up. (C) Seven-year follow-up radiograph showing widening of the radiolucent line underneath the tibial component (white arrows) but no progression to the stem.

cementation of the CCK prosthesis, a rotating hinge prosthesis was not necessary.

In revision TKA, the use of an intramedullary stem can provide the necessary load sharing (bypass load) and consequentially offload the remaining host bone and graft, simultaneously improving component stability ${ }^{6,13)}$.

Implant fixation techniques can be classified into three according to cement application on the implant: full cementation technique, hybrid fixation technique and surface cementation technique. Advantages of full cementation technique include immediate secure fixation and greater flexibility in placement of implants. It is also useful for antibiotic delivery in case of infection. One of the disadvantages is the difficulty of cement removal when an infection occurs. Greene et al. ${ }^{8)}$ and Sah et al. ${ }^{14)}$ achieved good results using the hybrid fixation technique in revision TKA. According to Cawley et al. ${ }^{15)}$, full cementation reduces cancellous stress under the baseplate, which facilitates bone resorption under the baseplate and decreases the possibility of aseptic loosening of the tibial component. Mumme et al. ${ }^{16)}$ suggested full cementation is advantageous for stable implant fixation in patients with impaired bone quality due to large bone defects or osteoporosis. Whaley et al. ${ }^{17)}$ reported on the results of TKA performed using the full cementation technique in 38 cases: the survival rate was $96.7 \%$ at 10 -year follow-up and $95.7 \%$ at 11 -year follow-up. Cemented stems increase the area of cement fixation to the bone and can be used in many different bone geometries; however, removal can be difficult. Uncemented stems that are not porouscoated cannot provide initial mechanical fixation and probably do not provide long-term biologic implant fixation ${ }^{18)}$. We used the full cementation technique because the implanted stem was a polished stem, not a porous coated one. The fully cemented polished stems did not cause any problems at the midterm followup, such as component loosening.

Bone defects are a challenging problem in most revision cases. Accurate defect assessment and proper implant and augment selection are important for successful revision TKA. Cement filling is commonly used with screws in patients with small bone defects and elderly patients ${ }^{19)}$. Brand et al. ${ }^{20)}$ recommended the use of cement for less than $50 \%$ surface defect with $10 \mathrm{~mm}$ thickness. For young patients who have a probability of re-revision, bone grafts can be used to maintain bone stock ${ }^{21)}$. Lotke et al. ${ }^{22)}$ reported good results of bone grafting in 48 cases. Metal augmentation is also used for more than $1 \mathrm{~cm}$ bone defects ${ }^{20)}$. Metal augmentation has some advantages such as easy application, elimination of the risk of nonunion and infection transmission and immediate stabilization $^{23)}$. In this study, metal augmentation was used in all cases. For large medial tibial defects, multiple block augmentation could be used with cement. This technique had not been introduced previously, but stability was maintained during follow-up without complications. The multiple metal augments were able to be well maintained by stable prosthesis fixation with the full cementation technique. Generally, large bone defects are treated by using a rotating hinge knee prosthesis. However, multiple block augmentation with a fully cemented CCK could be effective for management of large defects without a rotating hinge. Chung et al. $^{24)}$ reported on the use of medial multiple blocks for large defects; however, they used two blocks for the medial defect, not 3 or 4 more blocks. Augmentation with 3 or 4 blocks in the defect area could be possible only with use of the full cementation technique. 
Radiolucent lines were observed in $27.8 \%$ underneath the tibial component, which is thought to be due to the stress shielding effect caused by the firm fixation of the stem. Although the width of radiolucent lines was increased in 3 cases, they did not progress to the stem. A longer follow-up is required to evaluate further progression of the radiolucent lines.

Certainly, there are some limitations of our study that have to be considered when interpreting our data. The number of cases was too small, only mid-term follow-up was available and there was no comparison with the hybrid cementation technique. Therefore, studies involving more cases and longer follow-up periods are needed in the future.

\section{Conclusions}

Full cementation of a CCK prosthesis in revision TKA showed excellent clinical results. Radiolucent lines were observed in $27.8 \%$ underneath the tibial component but, there was no progression to cause loosening or instability.

\section{Conflict of Interest}

No potential conflict of interest relevant to this article was reported.

\section{References}

1. Mahomed NN, Barrett J, Katz JN, Baron JA, Wright J, Losina E. Epidemiology of total knee replacement in the United States Medicare population. J Bone Joint Surg Am. 2005;87: 1222-8.

2. Johnson AJ, Sayeed SA, Naziri Q, Khanuja HS, Mont MA. Minimizing dynamic knee spacer complications in infected revision arthroplasty. Clin Orthop Relat Res. 2012;470:2207.

3. Whittaker JP, Dharmarajan R, Toms AD. The management of bone loss in revision total knee replacement. J Bone Joint Surg Br. 2008;90:981-7.

4. Completo A, Simoes JA, Fonseca F, Oliveira M. The influence of different tibial stem designs in load sharing and stability at the cement-bone interface in revision TKA. Knee. 2008;15:227-32.

5. Meijer MF, Reininga IH, Boerboom AL, Stevens M, Bulstra SK. Poorer survival after a primary implant during revision total knee arthroplasty. Int Orthop. 2013;37:415-9.

6. Vince KG, Long W. Revision knee arthroplasty: the limits of press fit medullary fixation. Clin Orthop Relat Res. 1995; (317):172-7.

7. Kosse NM, van Hellemondt GG, Wymenga AB, Heesterbeek PJ. Comparable stability of cemented vs press-fit placed stems in revision total knee arthroplasty with mild to moderate bone loss: 6.5-year results from a randomized controlled trial with radiostereometric analysis. J Arthroplasty. 2017;32:197-201.

8. Greene JW, Reynolds SM, Stimac JD, Malkani AL, Massini MA. Midterm results of hybrid cement technique in revision total knee arthroplasty. J Arthroplasty. 2013;28:570-4.

9. Engh GA, Ammeen DJ. Bone loss with revision total knee arthroplasty: defect classification and alternatives for reconstruction. Instr Course Lect. 1999;48:167-75.

10. Insall JN, Dorr LD, Scott RD, Scott WN. Rationale of the Knee Society clinical rating system. Clin Orthop Relat Res. 1989;(248):13-4.

11. Radnay CS, Scuderi GR. Management of bone loss: augments, cones, offset stems. Clin Orthop Relat Res. 2006;446: 83-92.

12. Vasso M, Beaufils P, Schiavone Panni A. Constraint choice in revision knee arthroplasty. Int Orthop. 2013;37:1279-84.

13. Mabry TM, Hanssen AD. The role of stems and augments for bone loss in revision knee arthroplasty. J Arthroplasty. 2007;22(4 Suppl 1):56-60.

14. Sah AP, Shukla S, Della Valle CJ, Rosenberg AG, Paprosky WG. Modified hybrid stem fixation in revision TKA is durable at 2 to 10 years. Clin Orthop Relat Res. 2011;469(3):83946.

15. Cawley DT, Kelly N, Simpkin A, Shannon FJ, McGarry JP. Full and surface tibial cementation in total knee arthroplasty: a biomechanical investigation of stress distribution and remodeling in the tibia. Clin Biomech (Bristol, Avon). 2012; 27:390-7.

16. Mumme T, Marx R, Qunaibi M, Niethard FU, Wirtz DC. Surface pretreatment for prolonged survival of cemented tibial prosthesis components: full- vs. surface-cementation technique. Biomed Tech (Berl). 2006;51:95-102.

17. Whaley AL, Trousdale RT, Rand JA, Hanssen AD. Cemented long-stem revision total knee arthroplasty. J Arthroplasty. 2003;18:592-9.

18. Shannon BD, Klassen JF, Rand JA, Berry DJ, Trousdale RT. Revision total knee arthroplasty with cemented components and uncemented intramedullary stems. J Arthroplasty. 2003; 18(7 Suppl 1):27-32.

19. Ritter MA, Keating EM, Faris PM. Screw and cement fixa- 
tion of large defects in total knee arthroplasty: a sequel. J Arthroplasty. 1993;8:63-5.

20. Brand MG, Daley RJ, Ewald FC, Scott RD. Tibial tray augmentation with modular metal wedges for tibial bone stock deficiency. Clin Orthop Relat Res. 1989;(248):71-9.

21. Dorr LD, Ranawat CS, Sculco TA, McKaskill B, Orisek BS. Bone graft for tibial defects in total knee arthroplasty. Clin Orthop Relat Res. 1986;(205):153-65.

22. Lotke PA, Carolan GF, Puri N. Impaction grafting for bone defects in revision total knee arthroplasty. Clin Orthop Relat Res. 2006;446:99-103.

23. Brooks PJ, Walker PS, Scott RD. Tibial component fixation in deficient tibial bone stock. Clin Orthop Relat Res. 1984; (184):302-8.

24. Chung KS, Lee JK, Lee HJ, Choi CH. Double metal tibial blocks augmentation in total knee arthroplasty. Knee Surg Sports Traumatol Arthrosc. 2016;2:214-20. 